straints can operate at the level of political, legal, and constitutional limitations or at the level of individual personal predispositions. Develop a list of all constraints placed on the types of participation you have identified.

\section{Feedback 3: Constraints}

Constraints at the political/legal level may include: civil service examinations, campaign finance regulations, voter registration laws, single member districts, age restrictions.

Constraints at the individual level may include: mistrust of politics, low efficacy, lack of awareness, alienation.

\section{Instruction 4: Possible Solutions}

Now that you have identified the necessary information and become aware of the various constraints, it is possible to evaluate a range of possible actions the group might recommend to increase participation. The possible solutions may address changes at any or all of the legal, constitutional, and individual levels.

At this point it is highly desirable to be creative. Do not reject any idea, even if it initially seems absurd.

\section{Feedback 4: Possible Solutions}

Possible solutions might have included: Political/legal change: do nothing, pay people to participate, rewrite the Constitution, select office holders by lottery, initiate referendums on all issues, create ombudsmen positions, hold elections on weekends. Individual level change: do nothing, re-educate the public, hold political career days, televise government, give participation scholarships.

\section{Instruction 5: Criteria for Evaluation}

Establish criteria by which to judge the possible solutions. Criteria should be general in form, applicable across the board to all possible solutions. List at least five separate criteria.

\section{Feedback 5: Criteria for Evaluation}

Criteria might include: legality, timeliness, compatibility with democratic principles, feasibility, effectiveness, morality, cost (tangible/intangible).

\section{Instruction 6: Ranking the Solutions}

Develop a matrix in which you list the solutions down the side column, the valuative criterion across the top. Employ a rating measure (i.e., scale 1 through 5 where $1=$ excellent, $5=$ terrible or hi/ med/lo, etc. that fit the criterion) to fill in each cell in the matrix.

\section{Feedback 6: Ranking the Solutions}

The matrix provides a scheme to evaluate solutions in comparison to one another. The completed matrix reveals a ranking of all solutions given the group's valuative criterion. The group now has a clear indication as to which solution it must propose. Adhere to the ranking in the next instruction.

\section{Instruction 7: The Final Proposal}

The matrix evaluated solutions in general terms. The group may decide to eliminate the lower ranked at this time. Evaluate those remaining in terms of their compatibility with the original problem objectives. In moving toward a final decision, make certain that incompatible solu- tions are not included in the final proposal.

Prepare a proposal detailing the group's recommendation(s). The proposal will be presented to the foundation (foundation = class). The foundation will critically evaluate each proposal, then select one as most meritorious.

It is essential to be as professional, competent, comprehensive, and persuasive as possible during the presentation.

A typed report of the proposal will be submitted to the instructor at the time of group presentation. The typed report should include, in outline form: statement of proposal, with selection rationale; constraints identified; and any additional relevant information supporting final proposal.

\section{Reference}

Schleicher, D. P. 1973. Participant's Manual for Real-Nation Gaming. Columbus: Charles E. Merrill Publishing Company.

\section{About the Author}

Kathleen K. McQuaid is an assistant professor, department of politics and economics, University of Mansfield.

\title{
Rationally Persuasive Writing Is Like House Painting: It's All in the Preliminaries
}

\author{
Joel J. Kassiola, Brooklyn College of the City University of \\ New York
}

How can we teach undergraduate students the nature of rationally persuasive writing and instruct them on the nature of rational argument? One important suggestion is to express clearly the conclusion of an argument early in the written discussion. Therefore, I will state clearly my goal in this article: to help instructors in all fields of political science communicate effectively to their students the nature of a sound rational argument and how it is composed. I believe this to be the most important contribution of any course within the liberal arts curriculum because, once it is learned, students can apply this knowledge in other contexts.

I hope to inspire others to direct their energies to achieving this objective. As a community of teachers, we need a continuing dialogue address- ing ways to achieve understanding of the nature of rational argumentation.

I gladly share an analogy between rationally persuasive writing and house painting-an analogy I have successfully used in my classes for some time. I present the analogy early in the semester, but not during the first few class meetings. Although it is tempting to address the question of how to define and write a rational 
argument in the earliest sessions (before the meat of the course has begun), I think that the ideal time is after a sample paper has been written.

I alert my students during the first meeting that I will ask them to provide a sample of their writing early in the term so that their strengths can be determined and deficiencies detected early enough to work on during the remainder of the semester. If any students require additional assistance with their writing, the diagnostic sample can provide a signal to initiate a conference with the student and, if necessary, make a referral to the college writing center for more extensive help. It is unfair to assign students the usual single, lengthy term paper late in the semester when insufficient time remains to implement what is learned from the instructor's criticism. This is true in the extreme when the semester's term paper is returned at the course's final examination.

As my department's first evaluator in the grade appeal process, I have often encountered instructors who penalize students for not properly producing a rational argument in their written work, but who have given them little or no instruction in how to achieve this important aim. Sadly, teaching how to write persuasively seems to have suffered the same fate as the teaching of effective written expression in high school: few teachers attempt to do it, and few succeed among those who try. Simple justice would require that before we hold students accountable in their writing that they be taught the nature of the ideal presentation and give the intellectual means to succeed. They should also be informed of the criteria by which they will be evaluated and why these criteria are required.

I tell my students that the diagnostic writing sample will not be counted in determining their final grade so that they may be fully relaxed about the exercise. Furthermore, I specifically do not discuss the nature of rationality and how to write a rationally persuasive paper prior to their efforts so that I can learn the level of their comprehension and prior achievement at this task. The sample provides a benchmark with which to compare their final paper in order to determine the progress they have made. For the sample, I choose the first reading of the semester-no matter what it is-and ask the students to submit a rationally persuasive essay on any theme of their choice derived from that reading.

At this point, I get the usual questions with which all instructors are familiar: "When is the paper due?" "Do we need to provide footnotes?" and, inevitably, "How long should the paper be?" If we reflected upon why these questions are always asked instead of substantive questions about the content of the assignment, we would quickly understand why students who focus on these issues are unlikely to produce outstanding, rationally persuasive essays. Such inquiries by students are signs that they have a poor understanding of how to write persuasively and, therefore, must be instructed on the nature of this process before any successful written work will be forthcoming.

It is a mistake, I believe, for instructors to answer these misguided questions, giving the false appearance of legitimizing them. Furthermore, it is cruel to omit discussion of how to write a cogent rational argument while still expecting one.

My own way of dealing with the ubiquitous question about the length of the paper is to reply: "It depends on what claim you wish to defend." This answer may not be very helpful to uninformed students, but it does indicate that I will not provide them with a misleading escape from their rational responsibilities by giving them an arbitrary page limit. It also emphasizes the crucial component of defending their claims in making a rational argument.

I do not discuss the proper approach to writing persuasively until the students have made their own first attempt and I have evaluated their work in detail. I carefully note every error in their writing samples, including spelling and paragraph errors, absence of a title, neglect of opening introductory and concluding paragraphs, and inadequate referential and explanatory footnotes. I also point out any lack of adequate evidence to match the strength of the claim-assuming a claim has been made and some evidence has been provided (or even attempted).

I think my presentation on how to write persuasively is best appreciated by the students after I have returned to them what they thought was a good essay. After all the papers have been assessed and returned, I devote one entire class meeting to discuss how to write rationally. The date of this class is announced well in advance and its importance given proper advertisement.

When all the students receive their papers (and among my student population these seldom include any $A$ papers; most fall in the range between $C$ and $D$ ), the thoroughness of assessment captures their attention. This fills the class meeting devoted to rationally persuasive writing with much anticipation and intellectual energy, even excitement.

Rather than begin with a dry lecture on the nature of rationality and how it should inform the writing of arguments, I pose the question of whether anyone in the class has ever painted a room. Invariably, several students raise their hands. I try to select a student who has not spoken in class before and ask: "What is the first thing one must do when attempting to paint a room?" Usually, the student will say something like: "Get some paint" or "Get a brush" or "Put some covers on the floor." I submit that if they think more carefully about the proper way to paint, some activities must be done prior to these obvious ones, and I solicit more suggestions. I usually get a potpourri of ideas, from mixing the paint to wearing old clothes.

Sooner or later a student will suggest the necessity to clean the wall. I emphasize this idea by asking if the student-painters have ever read the extensive but extremely small printed directions on all cans of house paint - which no one seems to have ever done! I tell them that some of the printed material relates to "preparing the surface" prior to painting. This involves making sure the surface of the wall is clear of any possible obstructions to the new coat of paint adhering, any peeling paint that will take the new coat with it when it falls, and any cracks requiring repair. Also, atmospheric conditions must be 
appropriate for successful painting: it must not be too cold nor the wall too damp if the surface is to be properly prepared for effective house painting.

I go into detail about properly preparing the wall surface because my analogy is between preparing the surface of a wall for painting and "preparing the mind" before writing a rational argument. I point out that the key to house painting is realizing the essential role of the preliminaries before applying paint and that aside from cleaning up the brushes, closing up the paint cans, and picking up the covers-all of which can be considered the aftermath of house painting - the actual painting is the very last thing done! Successful house painting is all in the preliminaries. If these are not done, or not done properly, the project cannot be a success no matter how much effort is expended in the painting itself!

I then criticize the actual manner in which most students prepare for writing a rationally persuasive paper. I begin with the ever-present question about length. Their almost compulsive need to know the instructor's desired page length fills the void created by ignorance about rational argument; it provides students with a useful and comforting standard for when to terminate their efforts instead of the epistemologically required fitness between the stringency of the claims made and the adequacy of the evidence to support them. To a student confused or ignorant about rational argumentation, the instructor's reply of a fiveor ten-page limit is a lifesaver. Once students understand the nature of rational argument, however, they can understand the extraneousness of criteria they often use to conclude papers-page length and due datesand reject them.

Another common enemy to writing rationally is the "chronological record" strategy. Students frequently write their papers as a chronological record of the specific sequence in which their ideas occurred to them. Idea \#1 is presented first, followed by the second idea that hit them, followed by the third, and so on. One of the major points of my presentation is to emphasize that the rationally persuasive paper is not a chronological record but a logical presentation wherein the first idea they thought of might logically be required to appear third in support of their second idea and so on.

It is essential to stress the importance of the rational paper as a philosophical argument with conclusions buttressed by evidential propositions, and, furthermore, that the relationship between these two logical roles is critical to success. Once students understand the nature of rational argument, and that rationally persuasive papers must be argumentative, they will be able to discard their reassuring but erroneous strategies of exposition.

Most uninformed students infuse the writing of papers with so much anxiety that the actual writing becomes an exercise in anxiety reduction. Merely filling up pages or computer screens relaxes the tense student-author, creating the false sense of completing the assignment in fine fashion. I think this explains the common experience of instructors receiving papers that make no claim or have no point, except to give the student the satisfaction of alleviating the anxiety associated with a dreaded assignment. It also explains, I believe, the typical unsatisfactory paper containing the regurgitation of other people's ideas (often not accompanied by footnotes). Restating other people's concepts and claims fills up pages and is much less challenging than thinking up one's own ideas.

The fear and loathing of thinking itself is worthy of comment. I believe that most students are panic-stricken by rationally persuasive assignments because they sense that they do not know how to execute them and that their efforts are therefore doomed to failure. Add to this the painful experience of poor grades on papers in the past confirming their ignorance and fears of inadequacy, and students, indeed, have much to dread in such writing assignments. Ideally, a new, clear understanding of how to write papers will free them from debilitating anxiety and defeatism. In this way, students can gain the necessary confidence and control in their thinking to be creative, careful, and through in their writing-all necessary characteristics of successful per- suasive essays.

My last step is to describe what I think is the proper way to approach the writing of a rationally persuasive paper. I refer back to the crucial role of preparing the walls in house painting and emphasize the need to prepare the mind for writing so that formulating the argument in prose is the final task. I stress the need for a substantive title that conveys the main point of the argument. Most students omit such titles because they still have a "school assignment" model in mind: they write the name of the class and the instructor just as they did in grade school. They thereby avoid the thought-provoking activity of asking themselves what, indeed, is their main point and how can they use it in their title. A substantive title forces them to have a main point!

I then discuss the logical burden borne by the opening paragraph or paragraphs, which should introduce the theme or subject of the paper and, most importantly, the main claim made by the author. This claim provides the goal for the paper devoted to rational persuasion: adequate support of this claim should cause any reasonable reader to accept it based upon the supporting evidence provided by the author. I always ask the class how they know what the aim or goal of the paper will be before they have written it. This usually creates puzzled looks although I have had a few students knowledgeable enough to suggest writing the title and introductory paragraphs after the paper has been completed. This seems to be a small and obvious tip, yet most students regard it as a revelation!

While still on the point about writing the opening paragraphs, I discuss the importance of providing an analytical outline of the main points of the paper including its major thesis and reasoned evidence to support it. This stage requires the most "brainstorming," or creative intellectual effort; however, if this part of the rational argument is done well, written expression can be fine tuned later, and thereby made easier.

The typical student attempts to do what is impossible for most ordinary thinkers, attempting two demanding cognitive tasks-conceiving and formulating-simultaneously. No 
wonder most students are muddled and queasy during the process of writing rationally! Once these two different epistemological processes are separated in concept and time, the appropriate division of labor can occur. Brainstorming sessions can be undertaken with whatever stimulates creativity (whether it takes music, beverages, food, late night or early morning, etc.), and then formulating the text itself can be concentrated upon once the "preparation of the mind" has occurred with the construction of the analytical outline. If the mind has been fully prepared, the task of formulating the language to express the argument will be made as simple as possible.

I talk a great deal about care in choosing and expressing one's problem and thesis. Defining the problem will provide the focus of the argument and weed out from among nearly infinite ideas what is relevant. Statements that explain and defend the thesis must be included; all other possible statements should not. The problem itself becomes the standard of what is relevant to the argument and what is not.

The epistemological heart of the paper is not the thesis but its defense. When students are taught that it is reasoned evidence for their claim upon which the instructor (or any reader) will base their assessment, they will comprehend the need to attend to this part of rationally persuasive writing as thoughtfully, carefully, and thoroughly as they can.

I also emphasize what I call the "fitness" between the claim made and the evidence needed for persuasive adequacy. The stronger the claim-the more stringent it is-the greater the evidence required to make it rationally persuasive. In this context I explain the critical role played by such epistemologically important words as: "all," "most," "some," "perhaps," "may," etc. Also, greater scope or range of application of claims require greater evidence. This discussion about fitness between the claim and evidence is aimed at getting students to concentrate upon the evidence-providing component of their rationally persuasive essay. I stress that it is here that most of their care and effort should be directed.

The conclusion of the typical undergraduate's paper seems to exemplify what a student once told my class. He thought that every paper's last paragraph should have a "big finish," just as in any show business act. Therefore, he argued, one would be justified in saying something at the end that is entirely new and even more profound or startling than what was said in the rest of the paper. An example of this approach to writing is an article about sexism in America that concluded with the idea that: "this is why we need a revolution in America." I tell students we may, indeed, need a revolution in America but this claim, like all claims, must be argued for rationally and thus defended, and not left to explode like a firecracker in the last line of the essay.

The last paragraph of an essay should contain no new claims since by definition they cannot be discussed or defended. If students wish to say something new, it should not be in the final paragraph. The last part of a paper should-perhaps disappointingly to those with a show business perspective-merely summarize the main points of the paper's argument.

Of course, a great deal more can be said about paper writing than is possible in one class meeting. I worry, as do most instructors, about taking valuable class time from the subject of the course. After all, most political scientists, and instructors in general, are more committed to their subject fields than they are to the rational process per se. However, I ask: can we afford to do less and still call ourselves instructors of rational inquiry? Can we consider ourselves fair evaluators when most students are unaware of the criteria used to judge their work and how to produce written work that we would consider excellent?

I hope the house painting analogy will be useful to you in communicating how rationally persuasive papers should be written and in helping students develop their critical skills. By so doing, I believe we fulfill our most noble task as teachers-providing students with the means to be rational in their thought, expression, and action.

\section{References}

Popper, Karl R. 1968. Conjectures and Refutations: The Growth of Scientific Knowledge. New York: Harper and Row. Popper, Karl R. 1972. Objective Knowledge: An Evolutionary Approach. Oxford University Press.

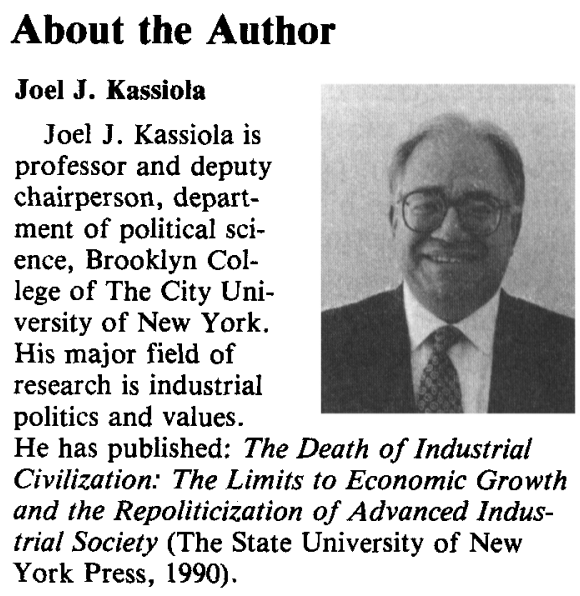

